\title{
Application of Green Management in High School Graduates' Voluntary Reporting
}

\author{
Li Tiantian \\ Department of Information Management \\ Rongchang Campus Southwest University \\ Chongqing, China \\ E-mail: 812205576@qq.com
}

\author{
Du Zhiguo * \\ Department of Information Management \\ Rongchang Campus Southwest University \\ Chongqing, China \\ E-mail: du_zhiguo@hotmail.com \\ * Corresponding Author
}

\begin{abstract}
Green management thinking can help high school students in the college entrance examination to obtain the ideal effect, can greatly improve the success rate of student volunteers. Through the application of the green management thought in the whole high school teaching, the research, the reduction, the development and the protection of the process to improve the present high school study, complete the school rules and regulations, improve the school assessment system. Facts prove that the idea of green management can effectively improve the quality of teaching, improve students' learning efficiency, and can better guide students to fill in the college entrance examination. Green management thinking can also guide the school to change the education orientation, formulate a reasonable teaching plan, adjust the allocation of teachers, and cultivate the talents with social needs. Therefore, the rational use of green management thinking in high school learning, can greatly change the existing teaching situation.
\end{abstract}

Keywords-Green management; intentional major; voluntary reporting; Senior High School; higher educational

\section{INTRODUCTION}

The thinking of green management was originated from the green tide uprising within the scope of the world in the 20th century, and the wave of green campaign had consecutively surpassed each other since the first environmental protection conference of the UN in 1972 (the Stockholm Conference) to the United Nations Earth Summit on Environment and Development conference in 1992 (the Rio de Janeiro Conference). The theory about green management has also achieved continuous development and improvement since the 1990s, and it now has been universally recognized as an important direction of the development of theories on management in the $21 \mathrm{st}$ century.

The notion of green management takes managerial cybernetics as the basis, stresses the essential requirement of management on "no pollution", implements the service tenet of "people orientation", and stimulates the managers to finish the construction of systems with "active consciousness". The educational "green management notion" generally means the managing thinking that the education managers conduct controls on the performance of educational management behavior and the effect of no pollution according to the principles of high efficiency, low consumption, democracy, and creativity. It is able to provide more reasonable and effect thinking for practice in the aspects including the decision-making system of the leaders in the schools, the information feedback system of the substratum, personnel system, teaching system, and the setting up of discipline structures, thus taking an exploring step for the sustainable development of the educational career.

The deeper reason for the occurrence of the problems in the managing work in senior high schools lies in the lacking of perfect modern guiding measures for the application for majors by the fresh graduates from senior high schools as well as traditional system of cultural management. Therefore, in order to solve the problem of difficulty in employment for students in colleges and universities, it should help the lost students from a most deeper perspective, the fundamental purpose of which should be the thinking of management on the major application of graduates in senior high schools, and this is also an issue to be stressed in the discussion in this article.

\section{THE ADVANTAGES OF GREEN MANAGEMENT IDEA}

Compared to traditional management thinking, the emphasized measurements of the notion of green management in the managing system of students in senior high school lie in that it will stress the guidance of the work of managing the application for major by fresh graduates from senior high schools after they have finished the entrance examination for university, and the largest change is the cultivation of the culture of school management system so as to do good work in the connections of all the levels of the responsible persons through training the related leaders to have green management notions, further improve the influential power of the fresh graduates from senior high schools in application for majors, and further play a decisive role of the green management notion during the process of instructions in senior high schools.

The notion of green management puts emphasis on the cultivation of the responsible consciousness of the leaders, the active consciousness of related responsible persons, and the autogenesis consciousness of the students, integrates the work of managing the major application by fresh graduates from senior high schools into a systemized implementation, and solves the problems of the students in the third year in the various senior high schools during the process of their application of their majors through a series of behaviors corresponding to norms, thus being able to help the fresh graduates from senior high school to do good preparatory work in the application for majors to be learned in higher educational institutions at early stages and prevent the frequent occurrence of "regrets for 
choosing wrong majors" by the students in universities and colleges.

The thinking of "taking precautions" generated under the instruction of the notion of green management. In the strict environment of review in senior high school, all the students in the third year know too little about the work related to the application for majors after they have finished the national examination for entrance to colleges and universities, but this is more a problem about the managing system of the school. Taking precautions means that the school should do well work in preparation and help and guide the diligent students in the third year to make plans for the future in the early stages of the national examination for entrance to colleges and universities. Firstly, they should improve the professional and skill qualities of related leaders and get to know well about the employment market for the work of enrollment of the colleges and universities in current era; and secondly, they should enhance the responsible consciousness of the responsible persons and publicize the information obtained whole-heartedly and at the earliest time so as to realize the system of "taking precautions" in the notion of green management.

\section{PROBLEMS IN THE CURRENT VOLUNTARY REPORTING}

Leaders in senior high schools are mostly not attaching enough importance to the application for majors by fresh graduates in the third year in senior high schools. The author thinks the deepest reason for the insufficient recognition by the leaders in senior high school lies in the current backward system of management culture of the senior high schools in our nation. Traditional education in senior high schools only stresses the cultivation of the cultural quality of the students, thus the thinking of the implementation of all the managers are forever unchanged under this kind of customary educational notion, and they only conduct intensive training on ability for increasing the enrollment rate of the graduates but never consider the importance of application for majors, so finally they could achieve nothing.

Large gaps exist between the enrollment rate as well as the employment rate of colleges and universities and the theoretical expected results in schools affected by this kind of educational thinking, and this kind of gap would also mistakenly influence higher educational institutions and senior high schools in their reevaluating their education on the students, which would recycle repetitively. The basis of the control theory of management of green management notion should be combined to implement the service tenet of "people orientation", stimulate the leaders to achieve the constructions of the system with "active consciousness", be able to effectively help the leaders in the school to make decisions and choices, and cultivate new modes for management educational thinking.

There is a lack of rigorous and institutionalized standards for management of education. Nowadays most senior high schools do not have related measures on the management of guiding fresh graduates in the third year in senior high school for applying for majors after finishing the national exam for enrollment to higher educational institutions. In addition, secondary educational management departments like the Department of Moral
Education do not connected sufficiently closely to the no. 1 person responsible for the students plus that the persons responsible for the students like the class advisors do not know enough about the individual students. In most of the schools currently in China, the secondary departments are under the direct management of the school, and it had been a long time that the management departments had disconnected with the persons actually responsible for the students in that the communication on information had been not smooth so that the educational management departments are unable to deliver the conditions of the universities, colleges, and markets in the future while the persons responsible for the students are unable to make feedback for the information or act as the bridge between the students and the educational management departments due to not comprehensively understand the students, which is also a most important problem in nowadays. The efficiency could only be improved through effective methods for guidance of management and implementation proposed through the discussion between the primary leaders and the professional technicians corresponding to the educational management departments in combination with communication in every step. Therefore, it is inevitable to construct systemized green educational management, establish green management notions, and achieve perfect communication on information.

The staffs in the secondary educational management departments and the persons responsible for the students do not have enough professional quality. In addition to the aforementioned leading thinking and the defects in systems, the professional quality of the staffs in the secondary educational management departments and the persons responsible for the students are still not able to meet the needs of green management notion. Therefore, it is also an important limit factor. The staffs in the important educational department of senior high school should have higher professional skills and be able to master the employment trend of the society, the enrollment plan of higher educational institutions, and the methods for training students to a comprehensive degree.

The diligent students in the third year in senior high school wish to be enrolled to the higher educational institutions they like to be trained to achieve high quality, and they also wish to enter the labor market to show what they have learned. Therefore, the staffs in the secondary educational management department should take their own professional competence to well deliver information to the students, while the persons actually responsible for the students should improve their own professional morality so as to understand the actual status of the students in detail and implement the work assigned by their senior leaders. Therefore, the professional quality of all the managing staffs could only be effectively enhanced under the help of integration of green management notions and highly efficient organization and conduction of renovations corresponding to the notion of green educational management.

\section{APPLICATION OF GREEN MANAGEMENT IN SCHOOL}

\section{A. Green education management system}

In order to establish a mode of green educational management in a real meaning and help the so many students in the third year in senior high school to step out 
of the difficulty in perplexed selection of schools and majors, a systemized green educational management system must be established so as to render corresponding responsible department to conduct good communication and connection with the persons actually responsible for students and jointly help the students in the third year in senior high school to get out of the dilemma. As to the systemized green educational management system, firstly it should to implement comment and judgment on the thinking of the primary leaders to manage decision making who are the persons responsible for students at the highest level and render them to make reasonable scheme for cultivation and education according to the social needs and put forward the most appropriated judgment in decision making.

In addition, trainings conforming to green management modes should be conducted in real work in addition to the perfection of the details of management systems and clarification of the concrete task in every phase during the process of management in actual work; secondly, the staffs in secondary management departments and faculties should actively respond to the concrete scheme for implementation proposed by the senior leaders, coordinate and cooperate from the lower level to upper lever through integration of the strength of all members, and know about the specific interests and actual capabilities of the students so as to provide corresponding support materials for the school to conduct direction on professional careers and help the students through showing them how to get onto the right path and supplying reasonable suggestions from the perspective of the students as the persons actually responsible for the students.

\section{B. Carry out the reform of phase matching}

How to improve the ability of guidance of the teachers and managers of the school? It is the fundamental step of the notion of green educational management to improve the ability of guidance of the teachers and managers of the school. Teachers and secondary managers are the managers and workers on the front line of education, and the level of their professional skills could directly affect the development of the students in the future, so it is vital for the guidance of the development of the students to improve the guidance abilities of the managers and works on the front line of education. Firstly, the professional quality of teachers and secondary managers should be improved continuously and training courses in the aspect of vocational skills should be developed based on certain periodicals and time; secondly, the training in the aspect of vocational moralities of the workers should be intensified so that they could help the students to solve problems and serve the students whole-heartedly; and their abilities should be improved from the aspects of vocational skills and professional moralities, only through which could they keep pace with the times and meet the actual needs of the students.

How to expand the size of secondary educational management department? It has been known that currently there are usually 2 to 3 persons working in the department responsible for the enrollment to higher educational institutions of the graduates in the third year in many senior high schools (often named as the Department of Moral Education). During the investigation on the employment market of the students in and the concrete status of higher educational institutions, it is impossible to meet the requirements for guaranteeing the high efficiency of works. Therefore, the size of this department should be expanded to be about 10 persons who should be assigned to do good works in the investigation on the needs of employers in labor force in the society, the scheme of training talents in higher educational institutions, and information integration so as to achieve collaboration from the internal with forces from outside and that the inferiors could receive directions from the superiors.

How to investigate and research on the employment market and the scheme for training talents in higher educational institutions? Its purpose is to explain the needs of the society and the higher educational institutions for the major application of students in their third year in senior high schools, master the needs of the market, and confirm the scope for choice, which could begin from the several aspects below: Firstly, detailed investigation and researches should be done on the tendency of the employment in the society at the beginning of every year so as to clarify the professional and moral quality of the talents the employers need; secondly, the actual status of the enrollment to higher educational institutions in every year, including the majors in the enrolling universities and colleges as well as the needs of the society and market in that year, should be analyzed and integrated so as to be the reference for next year; and the more important thing is to instantly know the planning and design of the schemes for training talents in higher educational institutions in China, deeply explore the potential problems, and summarize the specific requirements on training in all the universities and colleges, through which the needs of the society and higher educational institutions will be delivered to the students so that they could have some understanding on them and take it as the basis for the application of majors.

To give courses on psychological consultation, In addition to the several points mentioned above, to give courses on psychological consultation is also a brand new application of the notion of green educational management, and its changing lies in that it involves not only the communication between the students and professional teachers in psychological assistance but also the participation the persons actually responsible for the students. The mental status of students in the third year of senior high schools could be understood because it has some common rules and could show different characters in various kinds of phases. Mental consultation work should target these periodical characters and utilize the methods like psychological lectures, group guidance, and individual consultation to help the students to well adjust their status for review of lessons in addition that the persons actually responsible for the students should act as the indicative sign for the students losing their direction before the national examination for enrollment to higher educational institutions, provide most reasonable suggestions for their struggling goals according to the specific characters of individual students, and help the students to have a rather clear positioning for themselves according to the results of the evaluation on the real abilities provided by professional psychological consultants and teachers so that they could apply for majors in a targeted way after finishing the tests on the national examination for enrollment to higher 
educational institutions, thus relieving the students from the torturing pain incurred by the application for majors to be studies in universities and colleges.

\section{CONCLUSION}

The management of major application of fresh graduates from senior high schools should be the issue highly stressed by all schools, which is directly related to the course of the studying and researches by students in higher educational institutions and could directly affect the issue that the work of employment management of higher educational institutions does not correspond to the demands and needs of the labor markets in our nation. Therefore, how to do good work in major application of the students after the national examination for enrollment to higher educational institutions has become the issue that needs overall arrangements by all senior high schools.

In current period and under the guidance of traditional management notion, most of the students after finishing the national examination for enrollment to higher educational institutions feel distressed in the choice for application majors to be studied in universities and colleges. They are confused in choosing majors, and they are also afraid they could not be enrolled due to a too high goal set by the major they have applied for. Many students are now actively expecting their schools to take corresponding measures to help mitigate this problem. The application of green management notion may help the leaders in school to establish reasonable scheme of cultivation and education according to the needs of the society and make most appropriate decisions and judgment, thus enhancing the power of all faculties for ensuring the systematical conduction of the aforementioned work, improve the ability of the students in self recognition, and effectively help the students in the third year in senior high schools to confirm their goals and apply for majors. Therefore, the notification of enrollment from their favorite higher educational institutions could repay the sweat they used to diligently invest.

\section{ACKNOWLEDGMENT}

The authors wish to thank Southwest University. This article supported by "Fundamental Research Funds for the Central Universities"(project number: XDJK2016C048), this article supported by "southwest university youth fund project" (project number: 20700909).

\section{REFERENCES}

[1] Kim Byoungkyoo and White Leroy, "Green energy and green management: Towards social responsibility and sustainability", Journal of Nanoelectronics and Optoelectronics, v5, August 2010, pp:105-109.

[2] Lun Y.H. Venus, "Green management practices and firm performance: A case of container terminal operations", Resources, Conservation and Recycling, v55,April 2011,pp:559-566.

[3] Zaima Keiko, “Conditions to diffuse green management into SMEs and the role of knowledge support: Agent-based modeling", Journal of Advanced Computational Intelligence and Intelligent Informatics,v17,March 2013 pp:252-262.

[4] Li Weining, Wu Kunjin and Zhang Yining, "Relationship among stakeholders, green management, and performance", WIT Transactions on Information and Communication Technologies, 46 v3,2013, pp:2657-2663.

[5] Marouek Josef and Zeman Robert,“New concept of urban green management", Clean Technologies and Environmental Policy,v16, December 2014,pp:1835-1838.

[6] Teixeira Adriano Alves, "Engineering School at Bauru, Department of Production Engineering and Management", International Journal of Production Economics, v140,November 2012,pp:318-329.

[7] Trentin Alessio, Forza Cipriano and Perin Elisa, "Embeddedness and path dependence of organizational capabilities for mass customization and green management: A longitudinal case study in the machinery industry", International Journal of Production Economics,v169,November 2015,pp:253-276.

[8] Yang Jianjun, Zhang Feng and Jiang Xu, "Strategic flexibility, green management, and firm competitiveness in an emerging economy", Technological Forecasting and Social Change,v101, December 2015,pp: 347-356.

[9] Cosimato Silvia and Troisi Orlando, "Green supply chain management", TQM Journal,v27,March 2015,pp:256-276.

[10] Jiang Zhigang and Zhang Hua "Hierarchical network model for green remanufacturing management and case study", Systems Engineering and Electronics,v30,December 2008,pp:2417-2420.

[11] Tissayakorn Kittipong and Akagi Fumio, "Green logistics management and performance for Thailand's logistic enterprises", Proceedings of the IEEE International Conference on Industrial Technology,September 2014, pp:707-711.

[12] Mutingi Michael, "Developing green supply chain management strategies: A taxonomic approach", Journal of Industrial Engineering and Management,v6,2013, pp:525-546.

[13] Cai Zhengying,Yang Bin and Li Jiaheng, "A risk monitoring and control model for green engineering quality management", Advances in Information Sciences and Service Sciences, v4, October 2012, pp:381-388.

[14] Mathiyazhagan K, Diabat Ali and Al Refaie Abbas, "Application of analytical hierarchy process to evaluate pressures to implement green supply chain management", Journal of Cleaner Production, v 107,November 2015, pp:229-236.

[15] Swami S and Shah J, "Channel coordination in green supply chain management", Journal of the Operational Research Society,v64, March 2013,pp:336-351. 